\title{
Protective antioxidative effects of caffeic acid phenethyl ester (CAPE) in the thyroid and the liver are similar to those caused by melatonin
}

\author{
Agnieszka Kokoszko-Bilska ${ }^{1,3}$, Jan Stepniak' ${ }^{1}$ Andrzej Lewinski ${ }^{2,3}$ and Malgorzata Karbownik-Lewinska1,3*
}

\begin{abstract}
Background: Whereas oxidative reactions occur in all tissues and organs, the thyroid constitutes such an organ, in which oxidative processes are indispensable for physiological functions. In turn, numerous metabolic reactions occurring in the liver create favourable conditions for huge oxidative stress. Melatonin is a well-known antioxidant with protective effects against oxidative damage perfectly documented in many tissues, the thyroid and the liver included. Caffeic acid phenethyl ester (CAPE), a component of honeybee propolis, has been suggested to be also an effective antioxidant.

The aim of the study was to evaluate the effects of CAPE on Fenton reaction-induced oxidative damage to membrane lipids (lipid peroxidation, LPO) in porcine thyroid and liver, and to compare the results with protective effects of melatonin.

Methods: Thyroid and liver homogenates were incubated in the presence of CAPE (500; 100; 50; 10; 5.0; $1.0 \mu \mathrm{M})$ or melatonin $(500 ; 100 ; 50 ; 10 ; 5.0 ; 1.0 \mu \mathrm{M})$, without or with addition of $\mathrm{FeSO}_{4}(30 \mu \mathrm{M})+\mathrm{H}_{2} \mathrm{O}_{2}(0.5 \mathrm{mM})$.

The level of lipid peroxidation was measured spectrophotometrically and expressed as the amount of MDA + 4-HDA (nmol) per mg of protein.
\end{abstract}

Results: Whereas CAPE decreased the basal LPO in a concentration-dependent manner in both tissues, melatonin did not change the basal LPO level. When antioxidants were used together with Fenton reaction substrates, they prevented - in a concentration-dependent manner and to a similar extent - experimentally-induced LPO in both tissues.

Conclusions: Protective antioxidative effects of CAPE in the thyroid and the liver are similar to those caused by melatonin. CAPE constitutes a promising agent in terms of its application in experimental and, possibly, clinical studies.

Keywords: Caffeic acid phenethyl ester (CAPE), Melatonin, Oxidative stress, Lipid peroxidation (LPO), Antioxidant, Thyroid, Liver

\section{Background}

Whereas oxidative reactions occur in all tissues and organs, the thyroid gland constitutes such an organ, in which oxidative processes are indispensable for physiological functions, thyroid hormone biosynthesis included. It is estimated that huge amount of reactive oxygen species

\footnotetext{
* Correspondence: mkarbownik@hotmail.com

'Department of Oncological Endocrinology, Medical University of Lodz, 7/9

Zeligowski St, Lodz 90-752, Poland

${ }^{3}$ Polish Mother's Memorial Hospital - Research Institute,

281/289, Rzgowska St, Lodz 93-338, Poland

Full list of author information is available at the end of the article
}

(ROS), especially of hydrogen peroxide $\left(\mathrm{H}_{2} \mathrm{O}_{2}\right)$, are produced in the thyroid under physiological conditions, justifying the statement that the thyroid gland is an organ of "oxidative nature" [1,2]. However, with additional oxidative abuse caused by exogenous or endogenous prooxidants, increased oxidative damage to all major cellular components, such as lipids, proteins and DNA, may occur, leading to different thyroid diseases, cancer included [1-4].

In turn, numerous metabolic reactions occurring in the liver create favourable conditions for huge oxidative stress. ROS and reactive nitrogen species (RNS), generated during 
these processes, are very important factors, not only in the physiology, but also in the pathophysiology of the hepatocyte $[5,6]$. The significant role of increased oxidative damage in the pathogenesis of different liver diseases, such as viral hepatitis, alcoholic hepatitis, hemochromatosis, druginduced liver injury, hepatic insulin resistance, nonalcoholic fatty liver disease or hepatocellular cancer, has been demonstrated in many experimental and clinical studies [5-8].

Due to potential huge oxidative stress in both the thyroid and the liver, effective protective mechanisms should have been developed. In these organs, the antioxidative defence systems are very extensive and comprise both enzymatic and non-enzymatic antioxidants $[2,6]$. On the other hand, the use of various exogenous antioxidants in both tissues - under condition of increased oxidative stress - has been shown to be beneficial in experimental (in vitro or in vivo) studies $[2,5,9,10]$. Unfortunately, the applicability of different antioxidants in human thyroid or liver diseases has not been yet clearly confirmed in clinical studies and still no effective antioxidative medication is available for widespread use [6-8,10]. Moreover, some antioxidants, such as ascorbic acid (vitamin $\mathrm{C}$ ), present a dual nature, acting in different redox environment as an antioxidant or prooxidant [11].

Melatonin (N-acetyl-5-methoxytryptamine), produced in the pineal gland, as well as in numerous other tissues and organs, is a very well-known antioxidant and free radical scavenger, with protective effects against oxidative damage perfectly documented in many tissues, the thyroid and the liver included [9,12-16].

Caffeic acid phenethyl ester (CAPE), an active component of honeybee propolis extract, is structurally related to flavonoids and has been used as a traditional medicine for many years [17-19]. It is known to possess numerous biological activities including anti-inflammatory, antiviral and immunomodulatory properties [17-19]. In experimental studies, CAPE has been shown to inhibit the growth and metastasis of different types of tumor, to protect tissues from reperfusion injury in various ischemia-reperfusion models, and to suppress inflammation in a variety of tissues [20]. It has been suggested to be also an effective antioxidant [21]. CAPE might be even used as a protective agent against chemotherapy-induced and radiotherapy-induced toxicity [17].

The aim of the study was to evaluate the effects of CAPE on experimentally-induced oxidative damage to membrane lipids (lipid peroxidation, LPO) in porcine thyroid and liver homogenates, and to compare the results with protective effects of melatonin. Substrates of Fenton reaction $\left(\mathrm{Fe}^{2+}+\mathrm{H}_{2} \mathrm{O}_{2} \rightarrow \mathrm{Fe}^{3+}+{ }^{\cdot} \mathrm{OH}+\mathrm{OH}^{-}\right)-$the most basic reaction of oxidative stress - were used to induce oxidative damage to membrane lipids.

\section{Methods}

The procedures, used in the study, were approved by the Ethics Committee of the Medical University of Lodz, Poland.

\section{Chemicals}

Caffeic acid phenethyl ester (CAPE), melatonin, ferrous sulfate $\left(\mathrm{FeSO}_{4}\right)$ and hydrogen peroxide $\left(\mathrm{H}_{2} \mathrm{O}_{2}\right)$ were purchased from Sigma-Aldrich (St. Louis, MO). The ALDetect $^{\mathrm{TM}}$ Lipid Peroxidation Assay Kit for LPO was obtained from Enzo Life Science (Farmingdale, NY). All the used chemicals were of analytical grade and came from commercial sources.

\section{Animals}

Porcine thyroids and livers were collected from twenty one (21) animals at a slaughter-house, frozen on solid $\mathrm{CO}_{2}$ and stored at $-80^{\circ} \mathrm{C}$ until assay. Three independent experiments were performed. Therefore, three tissue pools were prepared, with seven (7) thyroid glands used for each homogenate pool.

\section{Incubation of thyroid and liver homogenates}

Thyroid and liver tissue were homogenized in ice cold $50 \mathrm{mM}$ Tris- $\mathrm{HCl}$ buffer $(\mathrm{pH}=7.4)(10 \%, \mathrm{w} / \mathrm{v})$, and then incubated for $30 \mathrm{~min}$ at $37^{\circ} \mathrm{C}$ in the presence of examined substances.

Tissue homogenates were incubated in the presence of:

Experiment I: CAPE (500; 100; 50; 10; 5.0; $1.0 \mu \mathrm{M})$ alone (to check its effect on the basal LPO) or with addition of Fenton reaction substrates $\left[\mathrm{FeSO}_{4}(30 \mu \mathrm{M})+\right.$ $\left.\mathrm{H}_{2} \mathrm{O}_{2}(0.5 \mathrm{mM})\right]$.

Experiment II: melatonin (500; 100; 50; 10; 5.0; $1.0 \mu \mathrm{M}$ ) alone (to check its effect on the basal LPO) or with addition of Fenton reaction substrates $\left[\mathrm{FeSO}_{4}\right.$ $\left.(30 \mu \mathrm{M})+\mathrm{H}_{2} \mathrm{O}_{2}(0.5 \mathrm{mM})\right]$.

The concentrations of $\mathrm{FeSO}_{4}(30 \mu \mathrm{M})$ and $\mathrm{H}_{2} \mathrm{O}_{2}(0.5 \mathrm{mM})$ were selected from our previous study [12].

The reactions were stopped by cooling the samples on ice. Each experiment was run in duplicate and repeated three times.

\section{Measurement of lipid peroxidation products}

Concentrations of malondialdehyde + 4-hydroxyalkenals (MDA + 4-HDA), as an index of LPO, were measured in tissue homogenates.

The homogenates were centrifuged at $3000 \mathrm{x} \mathrm{g}$ for $10 \mathrm{~min}$ at $4^{\circ} \mathrm{C}$. The supernatant was mixed with $650 \mu \mathrm{l}$ of a methanol:acetonitrile $(1: 3, \mathrm{v} / \mathrm{v})$ solution, containing a chromogenic reagent, N-methyl-2-phenylindole, and vortexed. After addition of $150 \mu \mathrm{l}$ of methanesulfonic acid $(15.4 \mathrm{M})$, the incubation was carried out at $45^{\circ} \mathrm{C}$ for $40 \mathrm{~min}$. The reaction between MDA + 4-HDA and Nmethyl-2-phenylindole yielded a chromophore, which 
was spectrophotometrically measured at the absorbance of $586 \mathrm{~nm}$, using a solution of 4-hydroxynonenal $(10 \mathrm{mM})$ as standard.

The level of LPO was expressed as the amount of MDA + 4-HDA (nmol) per mg of protein.

\section{Protein measurement}

Protein was measured, using Bradford's method [22], with bovine albumin as the standard.

\section{Statistical analysis}

Results are expressed as means \pm SE. Data were statistically analyzed, using a one-way analysis of variance (ANOVA), followed by the Student-Neuman-Keuls' test. The level of $\mathrm{p}<0.05$ was accepted as statistically significant.

Statistica for Windows 10.0 software was used for the statistical analysis.

\section{Results}

In both tissue homogenates, CAPE (used in concentrations of 500,100, 50, 10 and $5 \mu \mathrm{M}$ ) decreased the basal LPO in a concentration-dependent manner (Figures 1, 2 ), while melatonin (in all the used concentrations) did not change the basal LPO level (Figures 3, 4).

In all the experiments, Fenton reaction substrates $\left(\mathrm{FeSO}_{4}\right.$ and $\mathrm{H}_{2} \mathrm{O}_{2}$ ), added into the incubation medium, increased the level of LPO in both the thyroid (Figures 5,6 ) and the liver (Figures 7, 8).

Antioxidants, i.e. CAPE or melatonin, prevented - in a concentration-dependent manner - experimentallyinduced LPO in both the thyroid (Figures 5, 6) and the liver (Figures 7,8 ), when used in the same range of concentrations (i.e. $500,100,50$ or $10 \mu \mathrm{M}$ ).

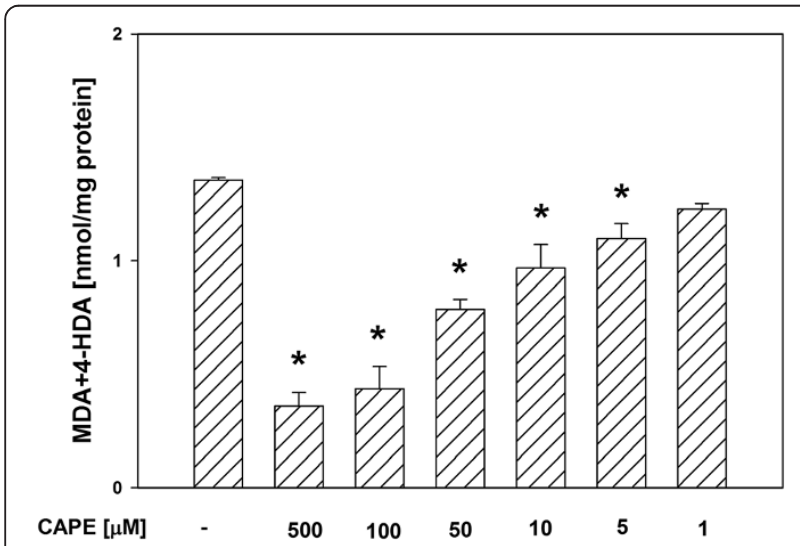

Figure 1 Concentrations of MDA + 4-HDA in porcine thyroid homogenates incubated for $30 \mathrm{~min}$ in presence of CAPE (500, $100,50,10,5,1 \mu \mathrm{M})$. Bars represent means \pm SEM of three independent experiments run in duplicates. ${ }^{*} p<0.05$ versus Controls.

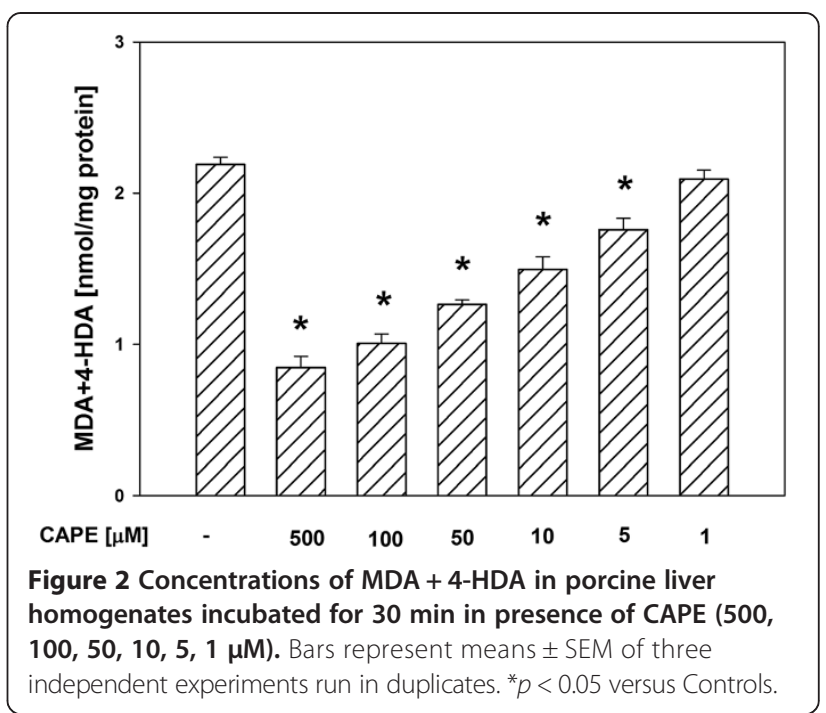

\section{Discussion}

According to our knowledge, the present study has been the first attempt to evaluate the effects of CAPE on the basal and experimentally-induced LPO in the thyroid and liver homogenates under in vitro conditions. Also for the first time, we compared the antioxidative activities of CAPE and melatonin in the thyroid.

The selection of the thyroid and the liver for such a study is justified by several factors. The thyroid gland is an organ in which ROS are widely involved in its function and even are indispensable for physiological processes [1,2]. Hydrogen peroxide acts as an electron acceptor at each step of thyroid hormone biosynthesis and is essential for activity of thyroperoxidase (TPO) the key enzyme in this process [1,2]. Also, the activity of antioxidative enzymes [superoxide dismutase (SOD),

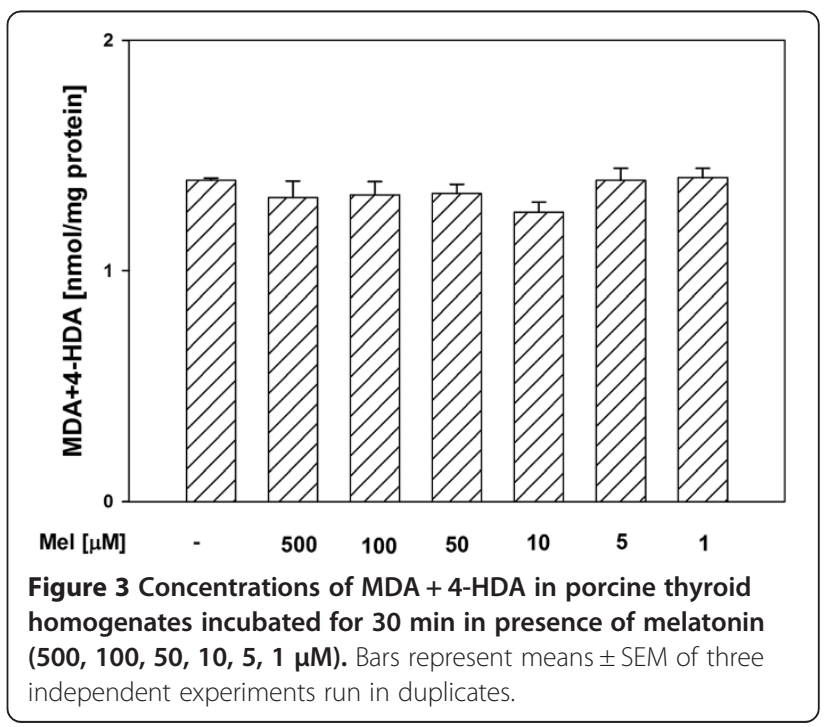






Figure 4 Concentrations of MDA + 4-HDA in porcine liver homogenates incubated for $30 \mathrm{~min}$ in presence of melatonin $(\mathbf{5 0 0}, \mathbf{1 0 0}, \mathbf{5 0}, \mathbf{1 0}, \mathbf{5}, 1 \mu \mathrm{M})$. Bars represent means \pm SEM of three independent experiments run in duplicates.

glutathione (GSH) peroxidase (GSH-Px) and catalase (CAT)] and antioxidative proteins (such as $\alpha$ - and $\gamma$ tocopherols, coenzyme Q, ascorbic acid and peroxiredoxins) has been well documented in the thyroid [1,2]. The liver plays an important role in detoxifying processes. It is also one of the organs with a higher oxygen consumption rate and therefore constitutively presents a greater expression of antioxidative enzymes than those with lower oxygen consumption [5]. Hepatocytes contain a variety of antioxidant enzymatic systems (SOD, GSH-Px, CAT), so they are able to reduce the amount of oxygen free radicals generated during cellular activity [6].

Consistently with our observations, many previous studies, conducted under in vivo conditions, have shown

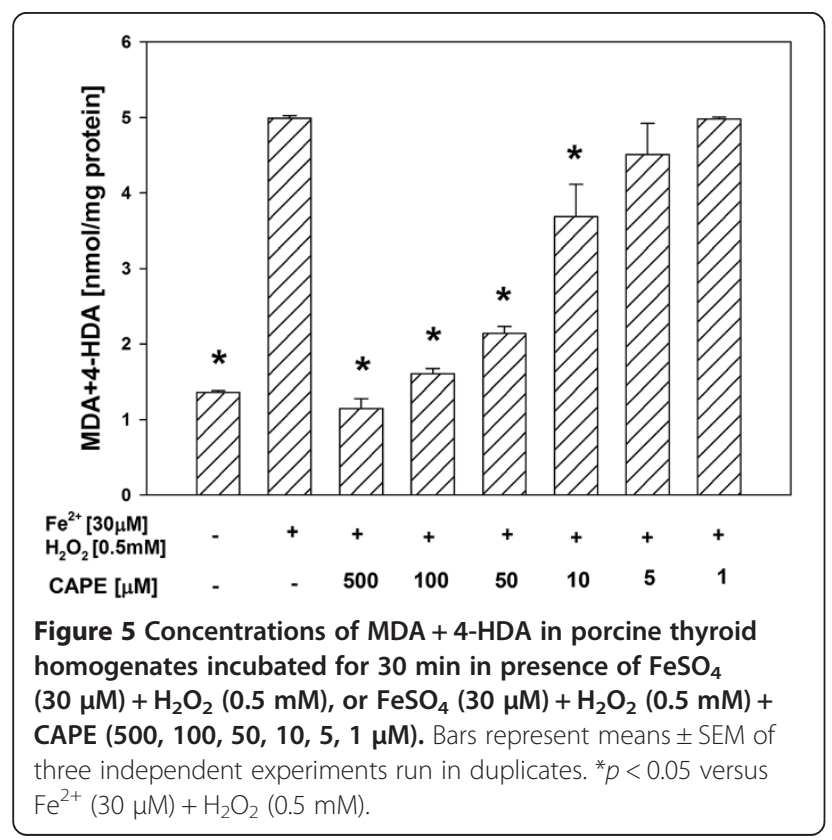

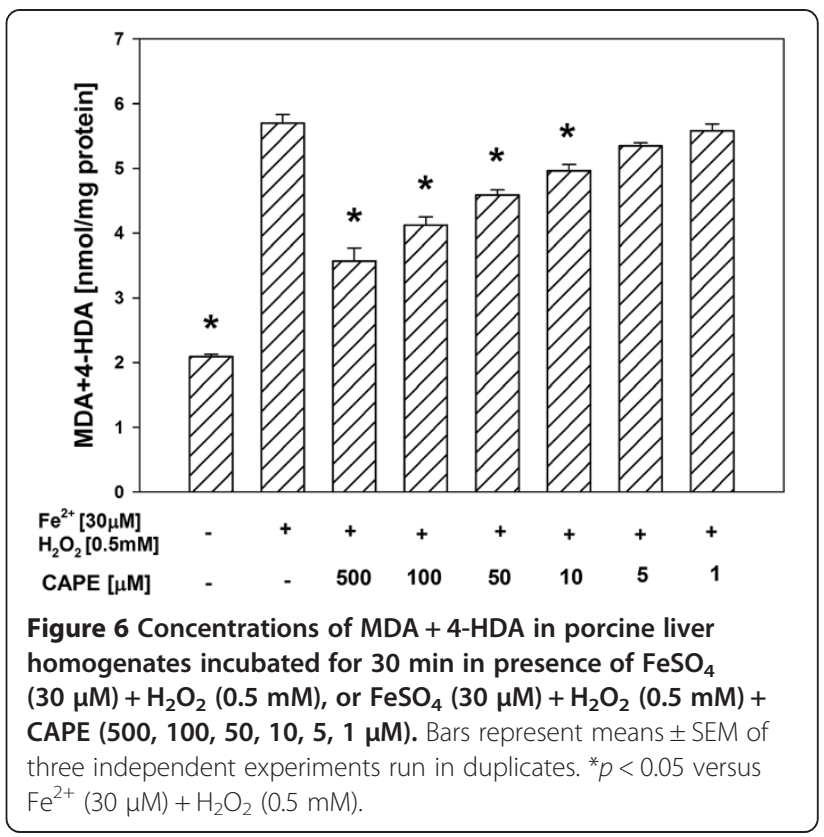

that CAPE exhibits antioxidant properties in different tissues. For example, CAPE, injected intraperitoneally (i.p.) to 10-12 weeks old male Wistar albino rats (10 $\mathrm{mg} / \mathrm{kg}$ body mass; 10-days administration), revealed protective effects on the aflatoxin B1-induced hepatoxicity by modulating free radical production: it decreased the total oxidant capacity (TOC) and glutathione S-transferase activity [23]. In another study, CAPE, given i.p. to 12 weeks old female Wistar albino rats $(10 \mu \mathrm{mol} / \mathrm{kg}$ body mass; 6days administration), prevented cisplatin-induced oxidative changes in the liver by reducing ROS production and increasing antioxidative enzyme activities (such as SOD,








Figure 8 Concentrations of MDA + 4-HDA in porcine liver homogenates incubated for $30 \mathrm{~min}$ in presence of $\mathrm{FeSO}_{4}$ $(30 \mu \mathrm{M})+\mathrm{H}_{2} \mathrm{O}_{2}(0.5 \mathrm{mM})$, or $\mathrm{FeSO}_{4}(30 \mu \mathrm{M})+\mathrm{H}_{2} \mathrm{O}_{2}(0.5 \mathrm{mM})+$ melatonin $(500,100,50,10,5,1 \mu \mathrm{M})$. Bars represent means \pm SEM of three independent experiments run in duplicates. ${ }^{*} p<0.05$ versus $\mathrm{Fe}^{2+}(30 \mu \mathrm{M})+\mathrm{H}_{2} \mathrm{O}_{2}(0.5 \mathrm{mM})$.

GSH-Px and CAT) [24]. Caffeic acid phenethyl ester also revealed the protective effects against liver damage induced by cigarette smoking [25], amikacin-induced nephrotoxicity [26] and methotrexate-induced hepatorenal oxidative injury [27].

Because iron is present in TPO and $\mathrm{H}_{2} \mathrm{O}_{2}$ is indispensable for TPO activity, the thyroid gland may be exposed under certain conditions - to excessive amounts of either $\mathrm{Fe}^{2+}$ or $\mathrm{H}_{2} \mathrm{O}_{2}$, or both, creating favorable conditions for additional Fenton reaction and, consequently, oxidative damage. Therefore, the observation - made by us in the present study - of the protective antioxidative effects of CAPE on Fenton reaction-induced LPO in the thyroid, seems to be of a great importance, especially that antioxidative properties of CAPE are mainly due to its free radical scavenging activity and ferrous ions chelating capacity [25]. Caffeic acid and its derivatives, such as CAPE, may chelate the ferrous ions with hydroxyl groups and then stabilizing the oxidized form of the metal ion [28].

In our study, CAPE revealed similar protective antioxidative effects to those caused by melatonin. These findings are in agreement with the results of previous studies performed under in vivo conditions. In 8-week old male Spraque-Dawley rats, melatonin $(100 \mu \mathrm{g} / \mathrm{kg}$ body mass daily, for 60 days $)$ or CAPE $(10 \mu \mathrm{mol} / \mathrm{kg}$ body mass daily, for 60 days) preinjections reduced - to a similar extent - retinal oxidative stress caused by a longterm exposure to electromagnetic radiation $(900 \mathrm{MHz})$ emitting by mobile phone [29]. In other study, melatonin and CAPE were efficient in delaying age-related cellular damage in cardiovascular system [30]. The aim of this study was to evaluate the effect of chronic melatonin
( $5 \mathrm{mg} / \mathrm{kg}$ body mass; injected daily for 95 days) and CAPE ( $15 \mathrm{mg} / \mathrm{kg}$ body mass; injected daily for 95 days) administration on the ultrastructural features, LPO levels, and enzymatic and nonenzymatic antioxidants in the heart and aorta of aged male Sprague-Dawley rats. Melatonin and CAPE administration significantly reduced the levels of MDA (as an index of LPO), increased the levels of the antioxidative enzymes and reduced agerelated histological changes (such as nuclear irregularity, mitochondrial degeneration myofilament disorganization and disruption) in both heart and thoracic aorta of aged rats [30].

Of a great importance is the fact, that in the present study, in both tissue homogenates, CAPE decreased the basal LPO in a concentration-dependent manner, while melatonin (in all the used concentrations) did not change the basal LPO level. It is well known (from many in vivo and in vitro studies) that melatonin is a perfect antioxidant because of its effective protective action against damaging effects of different prooxidants and the fact that under basal conditions it does not change the level of oxidative damage to macromolecules $[12,13,31,32]$. The observation - made by us in the present study - of the decreasing effect of CAPE on the basal LPO level, was unexpected and also undesirable. This finding may indicate that CAPE is not as perfect antioxidant as it seemed based on the results of earlier studies. According to our knowledge, only in two studies the effect of CAPE on the basal LPO was evaluated under in vivo conditions [24,33]. In the quoted studies, CAPE (injected for 6 days at a dose of $10 \mu \mathrm{mol} / \mathrm{kg}$ body mass [24] or for 3 days at the same dose [33]) did not change the basal LPO level $[24,33]$. This apparent disagreement between the above quoted studies and the present results may be explained by the fact that the in vitro effects can not be directly extrapolated to the in vivo conditions.

\section{Conclusions}

In conclusion, protective antioxidative effects of CAPE in the thyroid and the liver are similar to those caused by melatonin. CAPE constitutes a promising agent in terms of its application in experimental and, possibly, clinical studies.

\section{Abbreviations}

CAPE: Caffeic acid phenethyl ester; CAT: Catalase; $\mathrm{FeSO}_{4}$ : Ferrous sulfate; GSH: Glutathione; GSH-Px: Glutathione peroxidase; $\mathrm{H}_{2} \mathrm{O}_{2}$ : Hydrogen peroxide; LPO: Lipid peroxidation; RNS: Reactive nitrogen species; ROS: Reactive oxygen species; SOD: Superoxide dismutase; TOC: Total oxidant capacity; TPO: Thyroperoxidase.

\section{Competing interests}

The authors have declared that there is no conflict of interest.

\section{Authors' contribution}

$A K-B$ and MK-L designed the study and prepared the final version of the manuscript. MK-L supervised the conduction of the study. AK-B and JS carried out the experiments and performed the statistical evaluation. AK-B 
prepared the draft of the manuscript. AL revised the final version of the manuscript. All authors read and approved the final manuscript.

\section{Acknowledgements}

The research was supported by a grant from the Medical University of Lodz [Project No. 502-03/1-107-05/502-14-014 (502-02/1-168-01/502-14-014)].

\section{Author details}

${ }^{1}$ Department of Oncological Endocrinology, Medical University of Lodz, 7/9 Zeligowski St, Lodz 90-752, Poland. ${ }^{2}$ Department of Endocrinology and Metabolic Diseases, Medical University of Lodz, 281/289 Rzgowska St, Lodz 93-338, Poland. ${ }^{3}$ Polish Mother's Memorial Hospital - Research Institute, 281/289, Rzgowska St, Lodz 93-338, Poland.

Received: 24 April 2014 Accepted: 19 May 2014

Published: 5 June 2014

\section{References}

1. Karbownik M, Lewinski A: The role of oxidative stress in physiological and pathological processes in the thyroid gland; possible involvement in pineal-thyroid interactions. Neuro Endocrinol Lett 2003, 24:293-303.

2. Karbownik-Lewinska M, Kokoszko-Bilska A: Oxidative damage to macromolecules in the thyroid - experimental evidence. Thyroid Res 2012, 5:25.

3. Karbownik-Lewinska M, Stepniak J, Lewinski A: High level of oxidized nucleosides in thyroid mitochondrial DNA; damaging effects of Fenton reaction substrates. Thyroid Res 2012, 5:24.

4. Stepniak J, Lewinski A, Karbownik-Lewinska M: Membrane lipids and nuclear DNA are differently susceptive to Fenton reaction substrates in porcine thyroid. Toxicol In Vitro 2013, 27:71-78.

5. Tell G, Vascotto C, Tiribelli C: Alterations in the redox state and liver damage: hints from the EASL Basic School of Hepatology. J Hepatol 2013, 58:365-374.

6. Marí M, Colell A, Morales A, von Montfort C, Garcia-Ruiz C, Fernández-Checa JC: Redox control of liver function in health and disease. Antioxid Redox Signal 2010, 12:1295-1331.

7. Ivanov AV, Bartosch B, Smirnova OA, Isaguliants MG, Kochetkov SN: HCV and oxidative stress in the liver. Viruses 2013, 5:439-469.

8. Leung TM, Nieto N: CYP2E1 and oxidant stress in alcoholic and nonalcoholic fatty liver disease. J Hepatol 2013, 58:395-398.

9. Gesing A, Karbownik-Lewinska M: Protective effects of melatonin and Nacetylserotonin on aflatoxin B1-induced lipid peroxidation in rats. Cell Biochem Funct 2008, 26:314-319.

10. Milczarek M, Stepniak J, Lewinski A, Karbownik-Lewinska M: Potassium iodide, but not potassium iodate, as a potential protective agent against oxidative damage to membrane lipids in porcine thyroid. Thyroid Res 2013, 6:10.

11. Paolini M, Pozzetti L, Pedulli GF, Marchesi E, Cantelli-Forti G: The nature of prooxidant activity of vitamin C. Life Sci 1999, 64:273-278.

12. Karbownik M, Lewinski $A$ : Melatonin reduces Fenton reaction-induced lipid peroxidation in porcine thyroid tissue. J Cell Biochem 2003, 90:806-811.

13. Karbownik M, Gitto E, Lewinski A, Reiter RJ: Relative efficacies of indole antioxidants in reducing autoxidation and iron-induced lipid peroxidation in hamster testes. J Cell Biochem 2001, 81:693-699.

14. Karbownik M, Lewinski A, Reiter RJ: Anticarcinogenic actions of melatonin which involve antioxidative processes: comparison with other antioxidants. Int J Biochem Cell Biol 2001, 33:735-753.

15. Altintas R, Polat A, Parlakpinar H, Vardi N, Beytur A, Oguz F, Sagir M, Yildiz A, Duran Z: The effect of melatonin on acetylsalicylic acid-induced kidney and testis damage. Hum Exp Toxicol 2014, 33:383-395.

16. Chabra A, Shokrzadeh M, Naghshvar F, Salehi F, Ahmadi A: Melatonin ameliorates oxidative stress and reproductive toxicity induced by cyclophosphamide in male mice. Hum Exp Toxicol 2014, 33:185-195.

17. Akyol S, Ginis Z, Armutcu F, Ozturk G, Yigitoglu MR, Akyol O: The potential usage of caffeic acid phenethyl ester (CAPE) against chemotherapyinduced and radiotherapy-induced toxicity. Cell Biochem Funct 2012, 30:438-443.

18. Esrefoglu M, Iraz M, Ates B, Gul M: Melatonin and CAPE are able to prevent the liver from oxidative damage in rats: an ultrastructural and biochemical study. Ultrastruct Pathol 2012, 36:171-178.
19. Gong P, Chen F, Liu X, Gong X, Wang J, Ma Y: Protective effect of caffeic acid phenethyl ester against cadmium-induced renal damage in mice. J Toxicol Sci 2012, 37:415-425.

20. Kim H, Kim W, Yum S, Hong S, Oh JE, Lee JW, Kwak MK, Park EJ, Na DH, Jung Y: Caffeic acid phenethyl ester activation of Nrf2 pathway is enhanced under oxidative state: Structural analysis and potential as a pathologically targeted therapeutic agent in treatment of colonic inflammation. Free Radic Biol Med 2013, 65C:552-562.

21. Abdallah FB, Fetoui $H$, Fakhfakh F, Keskes L: Caffeic acid and quercetin protect erythrocytes against the oxidative stress and the genotoxic effects of lambda-cyhalothrin in vitro. Hum Exp Toxicol 2012, 31:92-100.

22. Bradford MM: A rapid and sensitive method for the quantitation of microgram quantities of protein utilizing the principle of protein-dye binding. Anal Biochem 1976, 72:248-254.

23. Akçam M, Artan R, Yilmaz A, Ozdem S, Gelen T, Nazıroğlu M: Caffeic acid phenethyl ester modulates aflatoxin B1-induced hepatotoxicity in rats. Cell Biochem Funct 2013, 31:692-697.

24. Iraz M, Ozerol E, Gulec M, Tasdemir S, Idiz N, Fadillioglu E, Naziroglu M, Akyol O: Protective effect of caffeic acid phenethyl ester (CAPE) administration on cisplatin-induced oxidative damage to liver in rat. Cell Biochem Funct 2006, 24:357-361.

25. Pekmez H, Kus I, Colakoglu N, Ogeturk M, Ozyurt H, Turkoglu AO, Sarsilmaz $M$ : The protective effects of caffeic acid phenethyl ester (CAPE) against liver damage induced by cigarette smoke inhalation in rats. Cell Biochem Funct 2007, 25:395-400.

26. Parlakpinar H, Ozer MK, Ucar M, Gaffaroglu M, Vardi N, Koc M, Acet A: Protective effects of caffeic acid phenethyl ester (CAPE) on amikacininduced nephrotoxicity in rats. Cell Biochem Funct 2006, 24:363-367.

27. Çakır T, Özkan E, Dulundu E, Topaloğlu Ü, Şehirli AÖ, Ercan F, Şener E, Şener G: Caffeic acid phenethyl ester (CAPE) prevents methotrexate-induced hepatorenal oxidative injury in rats. J Pharm Pharmacol 2011, 63:1566-1571

28. Gülçin I: Antioxidant activity of caffeic acid (3,4-dihydroxycinnamic acid). Toxicology 2006, 217:213-220.

29. Ozguner F, Bardak Y, Comlekci S: Protective effects of melatonin and caffeic acid phenethyl ester against retinal oxidative stress in long-term use of mobile phone: a comparative study. Mol Cell Biochem 2006, 282:83-88.

30. Eşrefoğlu M, Gül M, Ateş B, Erdoğan A: The effects of caffeic acid phenethyl ester and melatonin on age-related vascular remodeling and cardiac damage. Fundam Clin Pharmacol 2011, 25:580-590.

31. Karbownik M, Stasiak M, Zasada K, Zygmunt A, Lewinski A: Comparison of potential protective effects of melatonin, indole-3-propionic acid, and propylthiouracil against lipid peroxidation caused by potassium bromate in the thyroid gland. J Cell Biochem 2005, 95:131-138.

32. Karbownik M, Stasiak M, Zygmunt A, Zasada K, Lewinski A: Protective effects of melatonin and indole-3-propionic acid against lipid peroxidation, caused by potassium bromate in the rat kidney. Cell Biochem Funct 2006, 24:483-489.

33. Sırmalı M, Solak O, Tezel C, Sırmalı R, Ginis Z, Atik D, Agackıran Y, Koylu H, Delibas N: Comparative analysis of the protective effects of caffeic acid phenethyl ester (CAPE) on pulmonary contusion lung oxidative stress and serum copper and zinc levels in experimental rat model. Biol Trace Elem Res 2013, 151:50-58.

doi:10.1186/1756-6614-7-5

Cite this article as: Kokoszko-Bilska et al:: Protective antioxidative effects of caffeic acid phenethyl ester (CAPE) in the thyroid and the liver are similar to those caused by melatonin. Thyroid Research 2014 7:5. 